\title{
A Method for Calculating the Probability of Successfully Completing a Rocket Propulsion Ground Test
}

\author{
Bradley P. Messer \\ NASA, John C. Stennis Space Center, MS, 39520
}

\begin{abstract}
Propulsion ground test facilities face the daily challenge of scheduling multiple customers into limited facility space and successfully completing their propulsion test projects. Over the last decade NASA's propulsion test facilities have performed hundreds of tests, collected thousands of seconds of test data, and exceeded the capabilities of numerous test facility and test article components. A logistic regression mathematical modeling technique has been developed to predict the probability of successfully completing a rocket propulsion test. A logistic regression model is a mathematical modeling approach that can be used to describe the relationship of several independent predictor variables $X_{1}, X_{2}, . ., X_{k}$ to a binary or dichotomous dependent variable $Y$, where $Y$ can only be one of two possible outcomes, in this case Success or Failure of accomplishing a full duration test. The use of logistic regression modeling is not new; however, modeling propulsion ground test facilities using logistic regression is both a new and unique application of the statistical technique. Results from this type of model provide project managers with insight and confidence into the effectiveness of rocket propulsion ground testing.
\end{abstract}

\section{Nomenclature}

$\pi(x)=$ Logistic Regression model coefficient

$g(x) \quad=$ Logit

TDUR = test duration

$M A X P=$ maximum facility test pressure

\section{Introduction}

Today's increased emphasis on streamlining the propulsion system development process is increasing the pressure on propulsion system test centers to develop innovative approaches and increase utilization of current test facility assets. The role of rocket engine propulsion ground test facilities covers a wide landscape from dedicated single use rocket engine test stands supporting space shuttle and commercial launch systems thru multi-cell, multi-purpose rocket propulsion research and development test facilities. Full scale rocket engine test stands are normally several stories tall and designed to withstand several hundred thousand pounds of thrust, while component test cells are approximately twenty to thirty feet wide by twenty to thirty feet deep, with a structural blast wall separating the support equipment, instrumentation connections, power and safety equipment. Rocket propulsion ground test facilities have the capability to deliver a diverse selection of fuel and oxidizer propellants at low, medium, high and ultra high pressures with flows ranging from a few pounds per second up to a two thousand pounds per second. Additionally, propulsion test facilities are generally equipped to supply a wide range of high and low pressure gases, hydraulics, deluge water, potable water, high-speed video, low speed video and $35 \mathrm{~mm}$ photography. See Figure 1 for a schematic of a generic rocket propulsion test facility configuration.

Chief, Systems Engineering and Integration Division, EA50, Stennis Space Center, AIAA Senior Member 


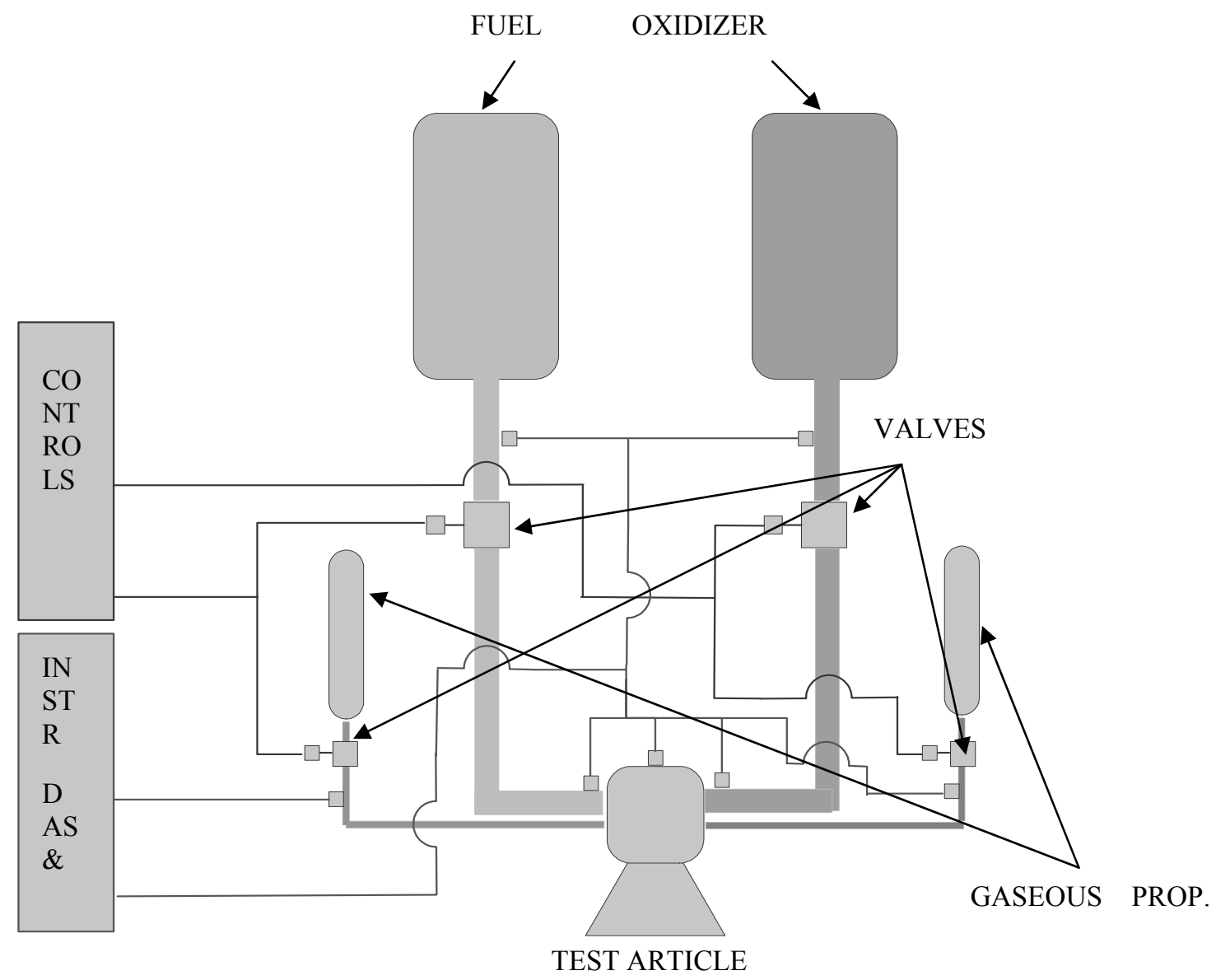

Figure 1. Generic Rocket Propulsion Test Facility

Test facility data acquisition systems on the whole have tremendous capacities and are the state-of-the-art in number of data channels and data storage capability. Test facility control systems are set up to provide a real-time graphical display of operations in progress, which can be monitored by test personnel in the test control center and in some cases at remote sites. Typical propellants found in rocket propulsion test facilities are liquid oxygen, liquid hydrogen, hydrogen peroxide and kerosene. Typical types of rocket propulsion tests are turbo-pump testing, injector testing, combustion testing and single engine testing.

In general a successful test is defined as a test that reaches full duration and the test article remains structurally sound. Off nominal performance by the test article is not considered a test failure if the test is not prematurely ended due to a violation of hardware constraint. A test anomaly can be described as a failure of a component in the facility or on the test article, such as an instrument. Anomalies are usually investigated and/or repaired prior to the next test. A test failure is defined as the termination of a test prior to reaching full duration due to any test termination event. These events could include automated facility or test article redline violations or manual observer-initiated cutoff.

Over the last decade rocket propulsion ground test facilities have performed a multitude of tests, collected reams of test data, and exceeded the operating capabilities of numerous components. Many valuable technical lessons have been learned, better propulsion test techniques developed, and various initiatives have been implemented to provide better propulsion test facility preventive maintenance to improve the quality of goods and parts used in the propulsion test facilities. Even with these advances, unexpected failures during testing still occur regularly due to the harsh environment in which the propulsion test facilities and propulsion systems operate, eroding the ability of the test facility to meet test goals, on schedule and on budget. 


\section{Predicting Successful Rocket Propulsion Tests}

Most propulsion system testing is undertaken to raise the level of technology maturity or expand the operating envelope. That lack of technology maturity in the propulsion test articles, combined with pushing the test facilities capabilities to their limits, tends to lead to an increase in facility breakdowns and unsuccessful tests. In today's environment of higher material and labor costs, chronic underfunding, short turnaround times and ill-defined customer requirements, knowledge is critical. Schedule estimates are one of the primary issues confronting rocket propulsion test facilities. Turnaround time between tests can be longer than anticipated. Facility failures during testing can be higher than expected. Propulsion systems customers no longer are just satisfied with successfully completing the testing; they want the testing complete within the original schedule estimate and on budget. The purpose of this paper is to provide an increased understanding of the probability and consequences of unexpected failures that occur during the testing phase of a rocket propulsion system development project. The research and model development provides information that project managers and test directors can use during the planning phase of a project to assess the potential schedule impacts caused by unexpected testing failures, thus allowing the project manager or test director to minimize the risk, minimize the cost, and maximize the probability of test success.

Most of the propulsion testing modeling efforts to date concentrated on the entire rocket propulsion test project lifecycle. Multiple attempts at modeling the complete propulsion test project lifecycle have been undertaken ${ }^{1,2}$. While technically accurate, each of the models suffers from incomplete and inconsistent data sets on which to base the models. Several attempts were made to improve the models, including the development of a tool for predicting test cell throughput capacity using queuing theory ${ }^{3}$, in which the testing process was modeled as a single server system (M/M/1) queuing process. Unfortunately, the model error rate of $17.2 \%$ was still quite high. While modeling the life cycle of a test project as it moves through the test facility is technically feasible, quality sources of data for each phase of the test project are not readily available, which has left the test facility operators unable to provide the customer accurate insight into the propulsion test facilities' ability to meet total project schedule milestones or individual test milestones. Sufficiently validated data does not exist to accurately model the entire rocket propulsion test project life cycle. However, a large set of quality data does exist covering the actual testing phase for propulsion test facilities. By concentrating on predicting the ability of a test facility to successfully perform tests in a timely manner using the available data, the inaccuracy and inconstancies of trying to model the entire propulsion test project lifecycle with inadequate data resources is eliminated, thus, providing the customer with insight into test facilities' ability to meet schedule milestones in the testing phase of the rocket propulsion test project lifecycle.

The goal of this paper is to provide decision makers with a technique to use when collecting relevant information for developing insight into a rocket propulsion test facilities' ability to meet test schedule milestones, providing the customer with a realistic test schedule with a high confidence level. The method for performing these calculations calls for the fitting of a logistic regression model to available test data. A test facility with sufficient operating history to provide a large data set was needed. Stennis Space Center's E-complex meets that criterion. Stennis' Ecomplex has performed hundreds of rocket propulsion tests over the last decade. The paper will concentrate on Stennis' E-complex test facilities large collection of recent data.

\section{Rocket Propulsion Facility Test Data}

Why use Stennis to develop the model? Stennis Space Center, located in south Mississippi, holds the responsibility for all NASA's rocket propulsion test activities ${ }^{4}$. The center's management responsibilities include NASA's rocket propulsion test assets and activities in Mississippi, Alabama, Ohio and New Mexico. SSC provides the leadership and stewardship roles in conducting rocket propulsion testing. Stennis tests and flight certifies rocket propulsion systems for current and future space vehicles and provides test services for both government and commercial customers. Stennis' propulsion test areas consist of the A, B and E test complexes. The A \& B test complexes provide large rocket engine test services, while E-complex provides small rocket engine and component test services. Stennis Space Center's E complex consists of three test facilities with seven test cells. Over the years, Stennis has amassed large quantities of data that reflect how and what it takes to operate propulsion test facilities. Safe and affordable space transportation is a top priority for NASA. Stennis Space Center continues to seek ways to reduce the risk associated with developing and testing technologies needed to access space safely and within budget. 
Specifically Stennis' E-complex has been chosen for this research effort due to the large volume of recent test activity. Hundreds of tests have been performed with thousands of seconds of data collected and a multitude of hardware issues over the last decade. The E complex consists of E1 shown in Figure 2, E2 shown in Figure 3 and E3 shown in Figure 4. Initial construction of the \$40 million NASA complex was begun on January 18, 1989. Originally known as the Component Test Facility (CTF), the E-complex propulsion ground test facility covers more than 20 acres in territory and was originally scheduled to be operational by mid-summer of 1991. Designed to test high-fidelity turbo-pump assemblies for the proposed heavy-lift Advanced Launch System (ALS) being jointly developed by NASA and the US Air Force, construction of the new test facility was to take two years. The ALS program eventually became the New Launch System (NLS) program, which unfortunately was cancelled. In late 1996 the Reusable Launch Vehicle (RLV) program was initiated. With this announcement, came $\$ 45$ million in the FY 97 budget to finish CTF, which was renamed E complex. The role of the Stennis Space Center and E complex in this new program was expanded to provide a facility for component level testing of the RLV engine valves, thrusters, and turbo-pumps. Additionally, the test facility was reconfigured to perform horizontal firings of rocket engines. While the RLV program has faded into history, E complex's role as a preeminent propulsion ground test site endures as we continue to work toward the NASA's Vision for Space Exploration.

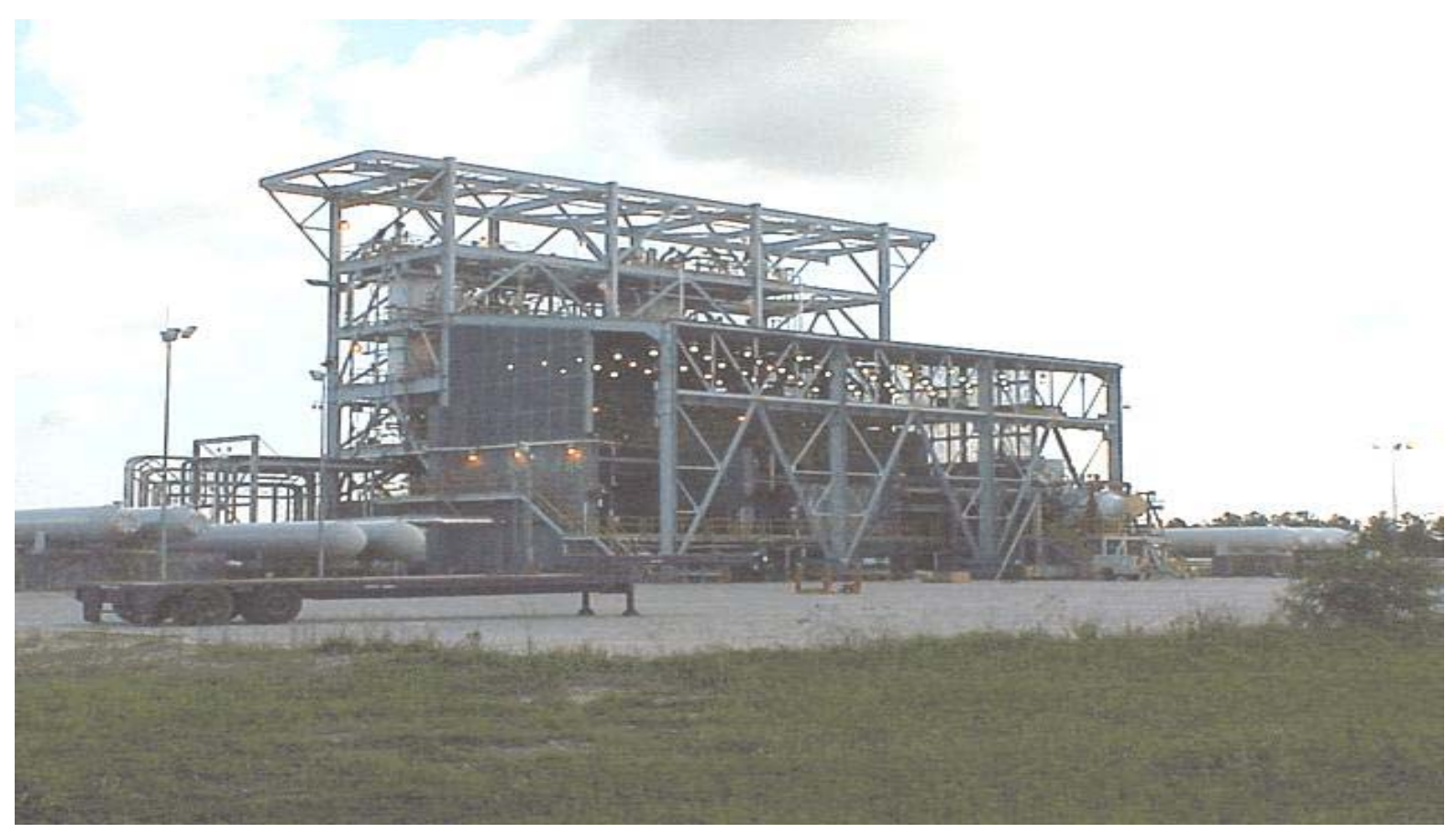

Figure 2. E1 Test Facility. 


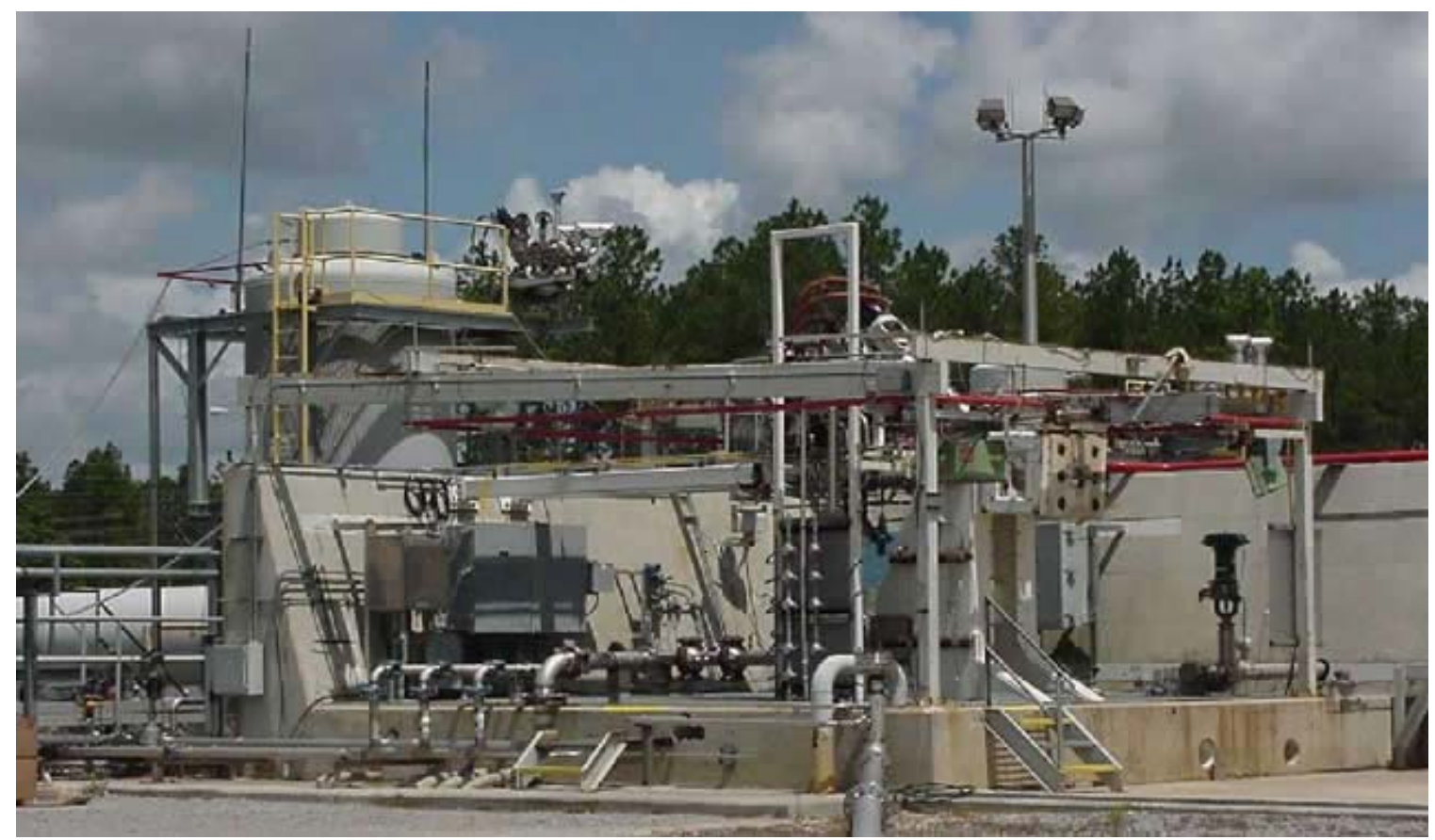

Figure 3. E2 Test Facility.

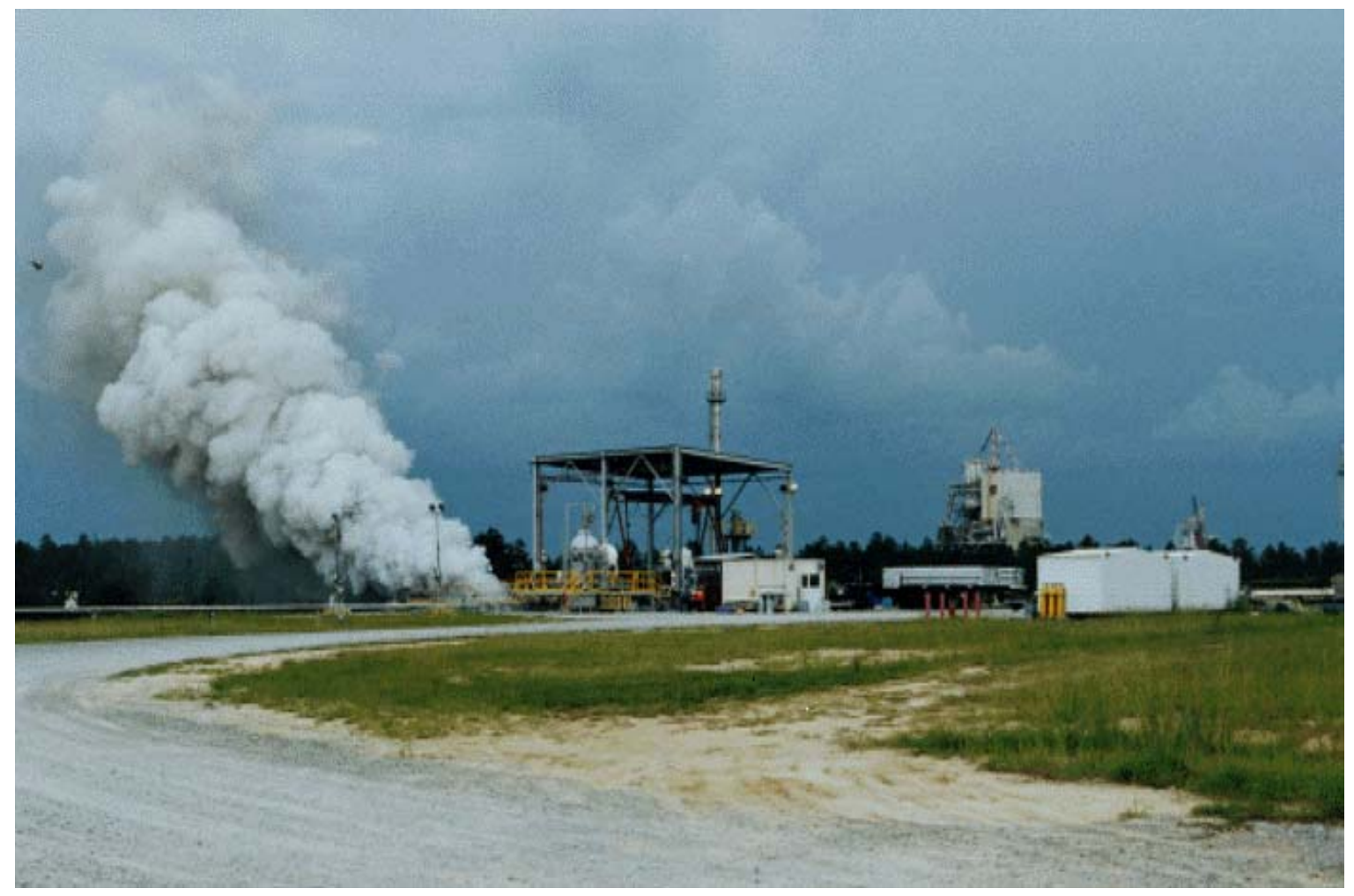

Figure 4. E3 Test Facility.

5

American Institute of Aeronautics and Astronautics

RELEASED - Printed documents may be obsolete; validate prior to use. 


\section{Development of the Logistic Regression Model}

Rocket propulsion test facilities need to instill a high level of confidence in their customers by providing insight into the propulsion test facilities ability to meet the test schedule milestones. To provide this insight a logistic regression model was developed to calculate the probability of successfully completing a given test.

A Logistic Regression model is a mathematical modeling approach that can be used to describe the relationship of several independent predictor variables (covariates) $\mathrm{X} 1, \mathrm{X} 2, \ldots . . \mathrm{Xk}$ to a binary or dichotomous dependent variable $\mathrm{Y}$, where $\mathrm{Y}$ can on be one of two possible outcomes ${ }^{5}$, in this case Success or Failure.

Conditional Probability

$$
P(Y=1 \mid x)=\pi(x)
$$

Logit of the Multiple Logistic Regression Model

$$
g(x)=\beta_{0}+\beta_{1} x_{1}+\beta_{2} x_{2}+\ldots+\beta_{p} x_{p}
$$

Logistic Regression Model:

$$
\pi(x)=e^{g(x)} /\left(1+e^{g(x)}\right)
$$

The use of logistic regression modeling was originally developed for epidemiologic research by Lemshow \& Homer $^{6}$ and Kelsey, Thompson, \& Evans ${ }^{7}$. The method is now commonly employed in many fields including biomedical research, business and finance, criminology, ecology, health policy, linguistics and wildlife biology.

As indicated in the previous paragraph the use of logistic regression is not new. However, logistic regression analysis has not been applied to rocket propulsion testing. Modeling propulsion test facilities using logistic regression is a new and unique application of the statistical technique. Results developed from models using this statistical technique will provide project managers with insight and a higher level of confidence in a propulsion test facilities' ability to meet test schedules.

The selection of independent variables for use in a Logistic Regression Model is the key component in the development of a useful tool for predicting the probability of successfully testing propulsion systems. Independent variables to consider include pressure, temperature, fuel type, oxidizer type, test duration, test article TRL level, instrumentation count and complexity, type of test article, and many others. If we were to look at the probability of completing multiple tests within a given period, independent variables such as number of work shifts, test turnaround duration, and number of predicted weather delays also become important variables to consider.

The following example uses a randomly selected set of 300 test data points collected from facility activation tests or propulsion hotfire tests conducted at Stennis Space Center over the last decade. Maximum facility propellant pressure and test duration were chosen as the independent variables. The dependent variable is the success or failure of the test.

Schedule durations for designing or constructing the propulsion test facilities are not to be considered. Test article testing requirements are considered to be mature and any changes to the facility or test article are considered to be minor. The definition of a successful test is defined as the test reaches full duration as defined in the test request and the test facility and test article retain their structural integrity. Performance of the test article beyond it maintaining structural integrity was not considered in the model.

Test Durations range from 1 to 700 seconds. Max Facility Test Pressure ranges from 15 psi to 8500 psi. Test Duration was grouped into one of twelve bins and Max Test Pressure was grouped into one of seven bins, as seen in table 1. A test's outcome is labeled as " $\mathrm{S}=1$ " for a successful test and a test failure is labeled as " $\mathrm{F}=0$ ". A subset of the data can be seen in table 2 . 


\begin{tabular}{|c|c|c|c|}
\hline Test Duration Bin & Test Duration Bin Range & $\begin{array}{c}\text { Max Facility Test Pressure } \\
\text { Bin }\end{array}$ & $\begin{array}{c}\text { Max Facility Test Pressure } \\
\text { Bin Range }\end{array}$ \\
\hline 1 & 1 to $15 \mathrm{sec}$ & 1 & 15 to 500 psi \\
\hline 2 & 16 to $30 \mathrm{sec}$ & 2 & 501 to $1500 \mathrm{psi}$ \\
\hline 3 & 31 to $45 \mathrm{sec}$ & 3 & 1501 to $3000 \mathrm{psi}$ \\
\hline 4 & 46 to $60 \mathrm{sec}$ & 4 & 3001 to $4500 \mathrm{psi}$ \\
\hline 5 & 61 to $75 \mathrm{sec}$ & 5 & 4501 to $6000 \mathrm{psi}$ \\
\hline 6 & 76 to $90 \mathrm{sec}$ & 6 & 6001 to $7500 \mathrm{psi}$ \\
\hline 7 & 91 to $120 \mathrm{sec}$ & 7 & Greater than $7500 \mathrm{psi}$ \\
\hline 8 & 121 to $180 \mathrm{sec}$ & & \\
\hline 9 & 181 to $225 \mathrm{sec}$ & & \\
\hline 10 & 225 to $300 \mathrm{sec}$ & & \\
\hline 11 & $301 \mathrm{sec}$ to $400 \mathrm{sec}$ & & \\
\hline 12 & Greater than $400 \mathrm{sec}$ & & \\
\hline
\end{tabular}

Table 1: Test Duration Bins and Maximum Facility Test Pressure Bins

\begin{tabular}{|c|c|c|c|c|c|c|}
\hline Test Number & $\begin{array}{c}\text { Success or } \\
\text { Failure }\end{array}$ & Test Duration & $\begin{array}{c}\text { Maximum } \\
\text { Facility Test } \\
\text { Pressure }\end{array}$ & $\mathrm{S}=1$ or $\mathrm{F}=0$ & $\begin{array}{c}\text { TDUR } \\
\text { Bin }\end{array}$ & $\begin{array}{c}\text { MAXP } \\
\text { Bin }\end{array}$ \\
\hline 1 & $S$ & 2.82 & 1750.00 & 1 & 2 & 1 \\
\hline 2 & $S$ & 3.00 & 716.00 & 1 & 2 & 1 \\
\hline 3 & $S$ & 4.00 & 850.00 & 1 & 2 & 1 \\
\hline 4 & $S$ & 5.00 & 70.00 & 1 & 1 & 1 \\
\hline 5 & $F$ & 5.00 & 113.00 & 0 & 1 & 1 \\
\hline 6 & $S$ & 5.00 & 200.00 & 1 & 1 & 1 \\
\hline 7 & $S$ & 5.00 & 200.00 & 1 & 1 & 1 \\
\hline 8 & $\mathrm{~S}$ & 5.00 & 200.00 & 1 & 1 & 1 \\
\hline * & * & $*$ & $*$ & * & * & * \\
\hline * & * & $*$ & $*$ & * & * & * \\
\hline * & * & * & * & * & * & * \\
\hline * & * & $*$ & $*$ & $*$ & $*$ & $*$ \\
\hline$*$ & * & $*$ & $*$ & * & * & * \\
\hline$*$ & * & * & * & * & $*$ & * \\
\hline 296 & $\mathrm{~S}$ & 700.00 & 400.00 & 1 & 2 & 12 \\
\hline 297 & $\mathrm{~S}$ & 700.00 & 400.00 & 1 & 2 & 12 \\
\hline 298 & $\mathrm{~S}$ & 700.00 & 400.00 & 1 & 2 & 12 \\
\hline 299 & $\mathrm{~S}$ & 700.00 & 400.00 & 1 & 2 & 12 \\
\hline 300 & $S$ & 1150.00 & 400.00 & 1 & 2 & 12 \\
\hline
\end{tabular}

Table 2: An example of the rocket propulsion test series data 


\section{Binary Logistic Regression: S-F versus TA Secs}

Logistic Regression analysis was performed using Test Duration and Max Test Pressure as the independent predictor variables and the Test Success or Failure as the dichotomous dependent variable. Solving the logistic regression yielded the following results ${ }^{8}$. TDUR represents Test Duration and MAXP represents Maximum Facility Test Pressure.

$\underline{\text { Response Information }}$

$\begin{array}{lccc}\text { Variable } & \text { Value } & \text { Count } & \\ \mathrm{S}=1 / \mathrm{F}=0 & 1 & 258 & \text { (Event) } \\ & 0 & 42 & \\ & \text { Total } & 300 & \end{array}$

Logistic Regression Table

\begin{tabular}{lcrcrrr} 
& & & & \multicolumn{2}{c}{ Odds } & \multicolumn{2}{c}{$95 \%$ CI } \\
Predictor & Coef & SE Coef & $Z$ & Ratio & Lower & Upper \\
Constant & 1.12574 & 0.416458 & 2.70 & & & \\
TDUR & 0.16277 & 0.078155 & 2.08 & 1.18 & 1.01 & 1.37 \\
MAXP & 0.10530 & 0.191383 & 0.55 & 1.11 & 0.76 & 1.62
\end{tabular}

Log-Likelihood $=-118.086$

The logistic regression model can now be defined as:

Logit of the Multiple Logistic Regression Model

$$
g(x)=1.12574+0.16277 T D U R(x)+0.10530 M A X P(x)
$$

Logistic Regression Model:

$$
\pi(x)=e^{1.12574+0.16277 T D U R(x)+0.10530 \operatorname{MAXP}(x)} /\left(1+e^{1.12574+0.16277 \operatorname{TDUR}(x)+0.10530 \mathrm{MAXP}(x)}\right)
$$

Furthermore from the model it can be concluded that Test Duration and Max Facility Test Pressure are significant predictors of Test Success/Failure. This can be further visualized in Table 3.

\begin{tabular}{|c|c|c|c|c|c|c|c|c|c|c|}
\hline \multicolumn{9}{|c|}{ Group } \\
\hline Value & & 1 & 2 & 3 & 4 & 5 & 6 & 7 & 8 & Total \\
\hline 1 & & & & & & & & & & \\
\hline & Observed & 27 & 64 & 33 & 31 & 31 & 29 & 31 & 12 & 258 \\
\hline & Expected & 28.8 & 58.9 & 38.5 & 31.0 & 28.2 & 29.1 & 32.0 & 11.5 & \\
\hline 0 & & & & & & & & & & \\
\hline & Observed & 9 & 8 & 13 & 5 & 1 & 3 & 3 & 0 & 42 \\
\hline & Expected & 7.2 & 13.1 & 7.5 & 5.0 & 3.8 & 2.9 & 2.0 & 0.5 & \\
\hline Total & & 36 & 72 & 46 & 36 & 32 & 32 & 34 & 12 & 300 \\
\hline
\end{tabular}

Table 3. Table of Observed and Expected Frequencies. 
A plot of the Logistic Regression Model derived in Equation (5) can be seen in Figure 5. The plot suggests that in general as the maximum facility pressure increases the likelihood of a successful test increases. The plot also, suggests as test duration increases the likelihood of a successful test increases.

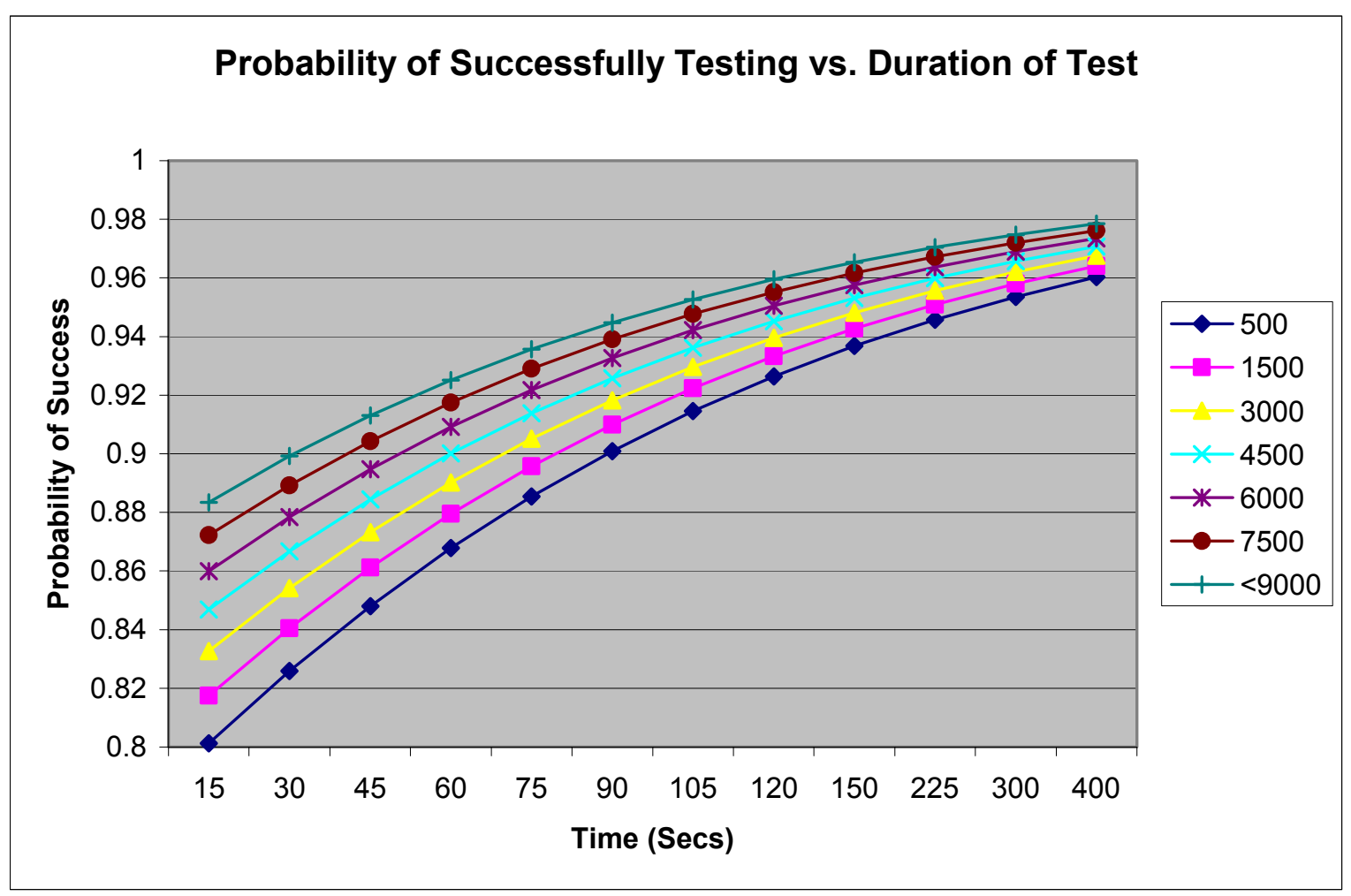

Figure 5. Probability of Successfully Testing vs. Duration of Test Given a Facility Pressure

The highest probability of a successful test (0.978) translates into a pressure of 7500 to 9000 psi with a test duration of over 300 seconds. The lowest probability of successful test (0.802) translates into a pressure less than $500 \mathrm{psi}$ with a test duration up to 15 seconds. Overall, a successful test is more likely than an unsuccessful test. The TDUR odds ratio $(\mathrm{OR})$ point estimate, $\mathrm{OR}=1.18$, indicates that a successful rocket propulsion test is 1.18 times more likely than an unsuccessfully test as the test duration increases. The $95 \%$ confidence interval suggests that successful tests could be as little as 1.01 times or as much as 1.37 times more likely than an unsuccessful test as the test duration increases. Additionally, the MAXP odds ratio (OR) point estimate, $\mathrm{OR}=1.11$, indicates that the likelihood of a successful rocket propulsion test increase as the maximum facility pressure increases. The $95 \%$ confidence interval suggests that the likelihood of a successful test could be as little as 0.76 times or as much as 1.62 times the original estimate, as the maximum facility test pressure increases. The results provide evidence to support the theory that most test failures occur early in a test series when the test article and facility are still searching for their respective sweet spots. The high probability of success as duration increases reflects the confidence that the facility and test article are ready to test for longer duration when the risk of the unknown has been reduced. As with most regression analysis, the larger the sample set, the better the fit of the model. As more data becomes available the accuracy of the Logistic Regression model will continue to improve. 


\section{Conclusion}

Propulsion test facilities face the daily challenge of scheduling multiple customers into limited test facility space. Test schedules provide customers information and knowledge identifying the propulsion test facilities level of confidence in estimating work. Attempts made in the past to model the complete lifecycle of a test project have met with little success. Each of the attempts suffered from incomplete or inconsistent data on which to base the models. By focusing on the actual test phase of the project rather than the formulation, design or construction phases of the project, the quality and quantity of available data increases dramatically.

Using a random sample of the data collected over the last decade a logistic regression model was developed to calculate the probability of successfully completing a rocket propulsion test. A more accurate depiction of specific propulsion test facilities capability can be achieved by sorting the data to only use data collected from that facility. If the data set was large enough, the data could be further refined to use only data taken from a specific type of testing.

This initial study presented on the previous pages was undertaken to prove the feasibility of using logistic regression to model rocket propulsion testing. The successful development of the example model clears the way for more complex logistic regression models to be developed in this area. From a customer perspective the results build confidence in the propulsion test facilities' ability to meet scheduled test milestones by providing an estimate on how successful the testing will be from the facilities' point of view. From a propulsion test facility's perspective the results impart insight into whether the test facilities are being over-extended and how it impacts the customers. This same logistic regression technique can be used with success at any other NASA or industry propulsion test facilities where large sets of test data can be found.

\section{Acknowledgments}

The author would like to thank Elizabeth Messer and Connie Shuler of the NASA Stennis Space Center for their help in locating and correlating the data used in this report.

\section{References}

${ }^{1}$ Douglas, F., "Risk Constrained Optimized Strategic Planner,” NASA Stennis Space Center, 1999.

${ }^{2}$ Franlkin, K., "Life Cycle Cost and Validation of Operations Modeling," Pipelines Program, NASA SSC, 2000

${ }^{3}$ Hines, M., "E3 Test Stand Cost Evaluation and Analysis Version 1.0," NASA Stennis Space Center, 2000

${ }^{4}$ Bruce, R. (ed.), Stennis Space Center Test Facilities Capabilities Handbook, $4^{\text {th }}$ Edition," New Business Office, NASA Stennis Space Center, 2001

${ }^{5}$ Hosmer, D.W., and Lemshow, S., Applied Logistic Regression, John Wiley \& Sons, New York, 2000.

${ }^{6}$ Lemeshow, S., and Homser, D.W., "The use of goodness-of-fit statistics in the development of logistic regression models," American Journal of Epidemiology, No. 115, 1982, pp. 92-106

${ }^{7}$ Kelsey, J.L., Thompson, W.D., and Evans, A. S., Methods in Observational Epidemiology, Oxford University Press, New York, 1986

${ }^{8}$ MINITAB, Statistical Software Package, Ver. 14.0, MINITAB Inc., 2004. 